\title{
Impact of menaquinone-4 supplementation on coronary artery calcification and arterial stiffness: an open label single arm study
}

\author{
Yuji Ikari ${ }^{*}$, Sho Torii', Atsushi Shioi ${ }^{2}$ and Toshio Okano ${ }^{3}$
}

\begin{abstract}
Background: Dietary intake of vitamin $\mathrm{K}$ has been reported to reduce coronary artery calcification (CAC) and cardiovascular events. However, it is unknown whether supplemental menaquinone (MK)-4 can reduce CAC or arterial stiffness. To study the effect of MK-4 supplementation on CAC and brachial ankle pulse wave velocity (baPWV).
\end{abstract}

Methods: This study is a single arm design to take $45 \mathrm{mg} /$ day MK-4 daily as a therapeutic drug for 1 year. Primary endpoint was CAC score determined using 64-slice multislice CT (Siemens), and the secondary endpoint was baPWV measured before and 1 year after MK-4 therapy.

Results: A total of 26 patients were enrolled. The average age was $69 \pm 8$ years and $65 \%$ were female. Plasma levels of phylloquinone (PK), MK-7, and MK4 were $1.94 \pm 1.38 \mathrm{ng} / \mathrm{ml}, 14.2 \pm 11.9 \mathrm{ng} / \mathrm{ml}$ and $0.4 \pm 2.0 \mathrm{ng} / \mathrm{ml}$, respectively, suggesting that MK-7 was the dominant vitamin $\mathrm{K}$ in the studied population. Baseline CAC and baPWV were $513 \pm 773$ and $1834 \pm 289 \mathrm{~cm} / \mathrm{s}$, respectively. At 1 year following MK-4 supplementation, the values were $588 \pm 872(+14 \%)$ and $1821 \pm 378 \mathrm{~cm} / \mathrm{s}(-0.7 \%)$, respectively. In patients with high PIVKA-2, $-18 \%$ annual reduction of baPWV was observed.

Conclusion: Despite high dose MK-4 supplementation, CAC increased $+14 \%$ annually, but baPWV did not change $(-0.7 \%)$. The benefits of MK-4 supplementation were only observed in patients with vitamin K insufficiencies correlated with high PIVKA-2 baseline levels, reducing baPWV but not CAC.

Trial registration: This study was registered as UMIN 000002760

Keywords: Vitamin K, Coronary artery calcification, Pulse wave velocity

\section{Introduction}

Coronary artery calcification (CAC) forms in the pathogenesis of atherosclerosis [1] and is associated with a higher risk of cardiovascular events [2, 3]. Annual changes of CAC-scores are considered to be relevant with severity of atherosclerosis [1, 2]. The vitamin $\mathrm{K}$ dependent Matrix Gla protein (MGP) plays a role as an inhibitor of soft tissue calcification [1, 4-6]. Patients with therapeutic vitamin $\mathrm{K}$ antagonist tended to have more valvular, vascular and coronary calcification [7, 8]. Observational studies in humans showed an inverse

\footnotetext{
* Correspondence: ikari@is.icc.u-tokai.ac.jp

'Department of Cardiovascular Medicine, Tokai University School of

Medicine, 143 Shimokasuya, Isehara 259-1193, Japan

Full list of author information is available at the end of the article
}

relationship between menaquinone (MK) intake and CAC in healthy elderly $[9,10]$. Phylloquinone (PK) supplementation was shown to retard the progression of CAC and had a beneficial effect on vascular stiffness in healthy adults with coronary artery calcification after 3 years of follow-up [11-13]. A randomized, doubleblind, placebo-controlled trial to investigate the effect of menaquinone-7 (MK-7) supplementation on MGP species showed a dose-dependent decrease of dephosphouncarboxylated MGP (dp-ucMGP) concentrations [14]. Furthermore, MK-7 improves arterial stiffness and elastic properties of the carotid artery [15]. These data may suggest that vitamin $\mathrm{K}$ administration may have beneficial effects on the vasculature. Supplementation studies using MK-4 has been few. This pilot study analyzed the 
impact of MK-4 supplementation on CAC and arterial stiffness.

\section{Methods}

\section{Patient selection and study protocol}

Patients with at least one coronary risk factor (coronary risk factors were defined as hypertension, diabetes mellitus, hypercholesterolemia, smoking, and family history of coronary artery disease) were enrolled. Exclusion criteria were patients with implantation of coronary stent or pacemaker, or inability to obtain correct coronary artery calcification (CAC) score or brachial ankle pulse wave velocity (baPWV) data. Written informed consent was obtained from each participant. The Institutional Review Board approved the study and all patients gave written informed consent. Medical histories, including prior myocardial infarction, prior percutaneous coronary intervention, prior coronary artery bypass graft surgery, prior heart failure, prior stroke, and hemodialysis, were obtained for each patient. The correlation between coronary artery calcification score, aortic stiffness and each factor was studied.

\section{Menqauinone-4 treatment}

A tablet containing $15 \mathrm{mg}$ of MK-4 (Eizai, Tokyo) was prescribed three times a day. This drug is approved for osteoporosis and is commercially available in Japan. If any side effects of the MK- 4 treatment occurred, it was to be reported to the study center. In the case of newly onset atrial fibrillation, MK- 4 could be stopped if vita$\min \mathrm{K}$ antagonist was indicated to prevent stroke.

\section{Cardiac multi-slice computed tomography data acquisition and analysis}

In all patients, a prospective non-enhanced coronary calcium scan was performed with a 64-slice MSCT scanner (Siemens, Munich, Germany). For quantitative assessment of coronary artery calcification, the Agatston score [16] was calculated, using a $3 \mathrm{~mm}$ CT slice thickness and a detection threshold of 130 Hounsfield units (HU) involving $\geqq 1 \mathrm{~mm}^{2}$ area/lesion (3 pixels). Total CAC score was determined by summing individual lesion scores from each of four anatomic sites (left main trunk, left anterior descending artery, left circumflex artery, and right coronary artery) [17]. The measurement was performed using syngo calcium scoring software supplied by Siemens. The inter-observer and intra-observer errors were reported as coefficient of variation of 2.1 and 1.3 [18]. CT was performed before starting MK-4 and 1 year after MK-4 treatment.

\section{Measurement}

Plasma was obtained from the patients in the morning after overnight fasting and stored at $-30{ }^{\circ} \mathrm{C}$. Vitamin $\mathrm{K}$
(PK, MK-4, and MK-7) was determined by the high-performance liquid chromatography-tandem mass spectrometry (LC-APCIMS/MS) method [19]. Total circulating uncarboxylated matrix gla protein (t-ucMGP) measurements were done by Dr. Vermeer's group. Intact parathyroid hormone, osteocalcin (OC), ucOC, NTX and bone type alkaline phosphatase (BAP) and high sensitive Creactive protein were measured by SRL Inc (Tokyo, Japan). Bone density was measured at lumbar vertebra using DSC-900FX (Hitachi-Aloka Medical, Tokyo). The ankle brachial index $(\mathrm{ABI})$ and baPWV were measured using BP-203 RPE (Omron-Colin, Kyoto).

\section{Endpoints}

The primary endpoint of this study was CAC score difference between baseline and 1 year after MK-4 treatment. The secondary endpoint was baPWV difference. Other plasma data and clinical data were obtained at baseline.

Table 1 Patient background

\begin{tabular}{ll}
\hline Number & 26 \\
Female gender & $65 \%$ \\
Age & $69 \pm 8$ \\
Height & $157 \pm 9$ \\
Weight & $57 \pm 11$ \\
Body mass index & $22.8 \pm 3.2$ \\
Current smoker & $27 \%$ \\
Diabetes mellitus & $15 \%$ \\
Hypertension & $73 \%$ \\
Dyslipidemia & $81 \%$ \\
History of myocardial infarction & $15 \%$ \\
Prior coronary artery bypass surgery & $4 \%$ \\
History of stroke & $4 \%$ \\
Ankle brachial index & $1.11 \pm 0.39$ \\
ba-pWV (cm/s) & $1834 \pm 289$ \\
Bone matrix & $1.053 \pm 0.251$ \\
\% Bone matrix & $117 \pm 20 \%$ \\
Coronary artery calcium score & $658 \pm 1049$ \\
Medications & \\
Aspirin & $42 \%$ \\
Statin & $58 \%$ \\
ACEl or ARB & $54 \%$ \\
Calcium antagonist & $58 \%$ \\
beta blocker & $19 \%$ \\
\hline Insulin & $8 \%$ pr bracha \\
\hline
\end{tabular}

ba-pWV brachial ankle pulse wave velocity $A C E I$ angiotensin converting enzyme inhibitor $A R B$ angiotensin receptor blocker 
Table 2 Baseline data

\begin{tabular}{|c|c|}
\hline Hemoglobin (g/dL) & $13.8 \pm 1.2$ \\
\hline Albumin $(\mathrm{g} / \mathrm{dL})$ & $4.2 \pm 0.3$ \\
\hline Triglyceride (mg/dL) & $136 \pm 82$ \\
\hline alkaline phosphatase (IU/L) & $223 \pm 59$ \\
\hline Blood urea nitrogen (mg/dL) & $15 \pm 3$ \\
\hline Creatinine (mg/dL) & $0.74 \pm 0.24$ \\
\hline ucOC (ng/ml) & $3.7 \pm 2.5$ \\
\hline $\mathrm{OC}(\mathrm{ng} / \mathrm{ml})$ & $7.5 \pm 2.7$ \\
\hline ucOC/OC ratio & $0.46 \pm 0.18$ \\
\hline PIVKA2 (mAU/mL) & $19 \pm 7$ \\
\hline intact parathyroid horomone $(\mathrm{pg} / \mathrm{mL})$ & $38.9 \pm 22.0$ \\
\hline Bone specific alkaline phosphatase $(\mu \mathrm{g} / \mathrm{l})$ & $13.8 \pm 6.5$ \\
\hline NTX (nmol BCE/L) & $16.9 \pm 5.1$ \\
\hline high sensitive C-reactive protein (mg/L) & $929 \pm 1132$ \\
\hline Osteoprotegerin (ng/mL) & $91.7 \pm 30.8$ \\
\hline oxidized low density lipoprotein ( $\mu \mathrm{g} / \mathrm{dL})$ & $104.9 \pm 11.9$ \\
\hline t-ucMGP (nmol/L) & $2907 \pm 1333$ \\
\hline PK (ng/mL) & $1.94 \pm 1.38$ \\
\hline MK-7 (ng/mL) & $14.2 \pm 11.9$ \\
\hline MK-4 (ng/mL) & $0.4 \pm 2.0$ \\
\hline
\end{tabular}

ucOC uncarboxylated osteocalcin

OC osteocalcin

PIVKA2 protein induced by vitamin $\mathrm{K}$ absence or antagonist- 2

NTX collagen type 1 cross-linked N-telopeptide

$t$-uCMGP total circulating uncarboxylated matrix gla protein

$P K$ philloquinone, $M K$ menaquinone

\section{Statistics}

We present continuous variables as mean \pm standard deviation in normal distribution or median and interquartile range. Categorical variables were presented as absolute numbers and percentages. Statistical analysis was performed with SAS version 9.2, (SAS Institute, Inc., Cary $\mathrm{NC})$. This study was registered as UMIN 000002760.

\section{Results}

A total of 26 patients were enrolled. Baseline characteristics are shown in Table 1 . The average age was $69 \pm 8$ years and $65 \%$ were female. Diabetes was $15 \%$ and the ankle brachial index was $1.11 \pm 0.39$. Baseline baPWV was $1834 \pm 289$ and the CAC score was $513 \pm 773$ (median 264 [48-484]).

Baseline blood test data are shown in Table 2. Uncarboxylated osteocalcin (ucOC) was $3.7 \pm 2.5 \mathrm{ng} / \mathrm{ml}$ and PIVKA2 was $19 \pm 7 \mathrm{mAU} / \mathrm{mL}$. Plasma levels of PK, MK-7, and MK4 were $1.94 \pm 1.38 \mathrm{ng} / \mathrm{ml}, 14.2 \pm 11.9 \mathrm{ng} / \mathrm{ml}$ and $0.4 \pm 2.0 \mathrm{ng} / \mathrm{ml}$, respectively. This suggests that MK-7 was the dominant vitamin $\mathrm{K}$ in the studied population.

CAC and baPWV data before and after MK-4 treatment are shown in Table 3. CAC significantly increased despite the MK-4 treatment and baPWV did not change (Fig. 1). The patients were divided into categories of baseline vitamin $\mathrm{K}$ insufficiency levels based on PIVKA2 or ucOC indicators. Regardless of the baseline level of PIVKA-2 or ucOC, CAC similarly increased in each group. To the contrary, baPWV was reduced significantly by MK-4 supplementation in patients with a high PIVKA-2 baseline (Fig. 2). However, the reduction was not observed in patients with low PIVKA-2. A similar pattern was observed with baseline ucOC levels, but it was not statistically significant (Fig. 3).

\section{Discussion}

Despite high dose MK-4 supplementation, CAC increased $+14 \%$ annually, but baPWV did not change $(-0.7 \%)$. CAC similarly increased annually irrespective of baseline vitamin $\mathrm{K}$ insufficiency. The MK-4

Table 3 Change after 1 year MK-4 supplementation

\begin{tabular}{|c|c|c|c|c|c|c|c|c|}
\hline$\overline{C A C}$ & & $\mathrm{~N}$ & Pre & 1 year & Difference & \%Difference & Paired $P$ value & Baseline $P$ value \\
\hline Total & & 26 & $513 \pm 773$ & $588 \pm 872$ & $72 \pm 143$ & $+14 \%$ & 0.018 & \\
\hline PIVKA2 & $\leqq 23$ & 22 & $421 \pm 543$ & $481 \pm 610$ & $60 \pm 132$ & $+14 \%$ & 0.052 & 0.64 \\
\hline PIVKA2 & $>23$ & 4 & $1010 \pm 1558$ & $1151 \pm 1761$ & $141 \pm 204$ & $+14 \%$ & 0.26 & \\
\hline ucOC & $<4.5$ & 19 & $348 \pm 448$ & $402 \pm 515$ & $55 \pm 139$ & $+16 \%$ & 0.11 & 0.38 \\
\hline ucOC & $\geqq 4.5$ & 7 & $947 \pm 1232$ & $1064 \pm 1387$ & $117 \pm 157$ & $+12 \%$ & 0.09 & \\
\hline PWV & & $\mathrm{N}$ & Pre & 1 year & Difference & & Paired $P$ value & Baseline $P$ value \\
\hline Total & & 26 & $1834 \pm 289$ & $1821 \pm 378$ & $-12.7 \pm 263$ & $-0.7 \%$ & 0.811 & \\
\hline PIVKA2 & $\leqq 23$ & 22 & $1826 \pm 280$ & $1872 \pm 379$ & $47 \pm 226$ & $+2.6 \%$ & 0.34 & 0.79 \\
\hline PIVKA2 & $>23$ & 4 & $1882 \pm 379$ & $1542 \pm 248$ & $-340 \pm 164$ & $-18 \%$ & 0.026 & \\
\hline ucOC & $<4.5$ & 19 & $1859 \pm 293$ & $1882 \pm 410$ & $22 \pm 261$ & $+1.2 \%$ & 0.71 & 0.26 \\
\hline ucOC & $\geqq 4.5$ & 7 & $1766 \pm 288$ & $1659 \pm 220$ & $-107 \pm 240$ & $-6.1 \%$ & 0.28 & \\
\hline
\end{tabular}




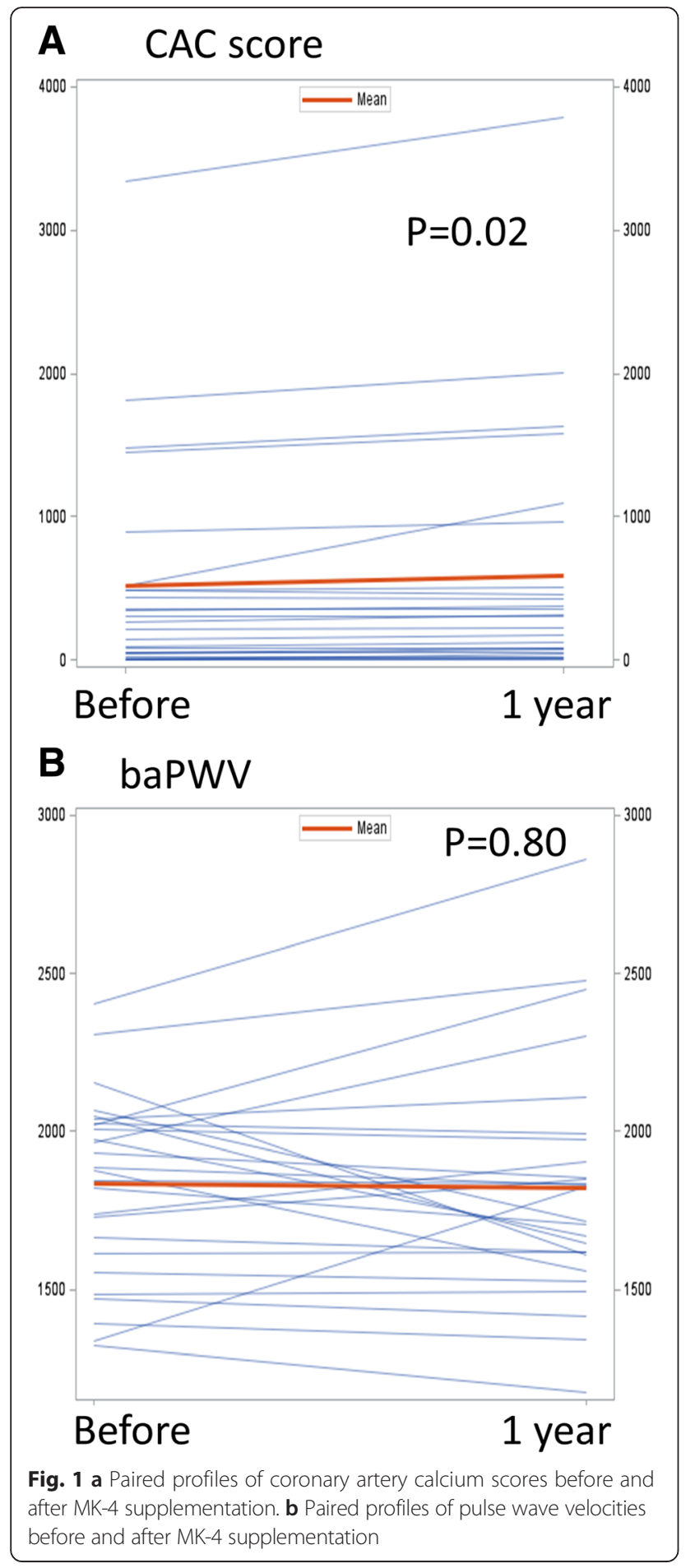

supplementation improved baPWV only in patients with vitamin $\mathrm{K}$ insufficiency.

An annual increase of CAC was reported as $17 \%$ in the meta-analysis [20]. The mean annual CACprogression reported in the literature ranges from 24 to $51 \%$ and has a large inter-individual variation depending on many factors such as the baseline CAC-score,

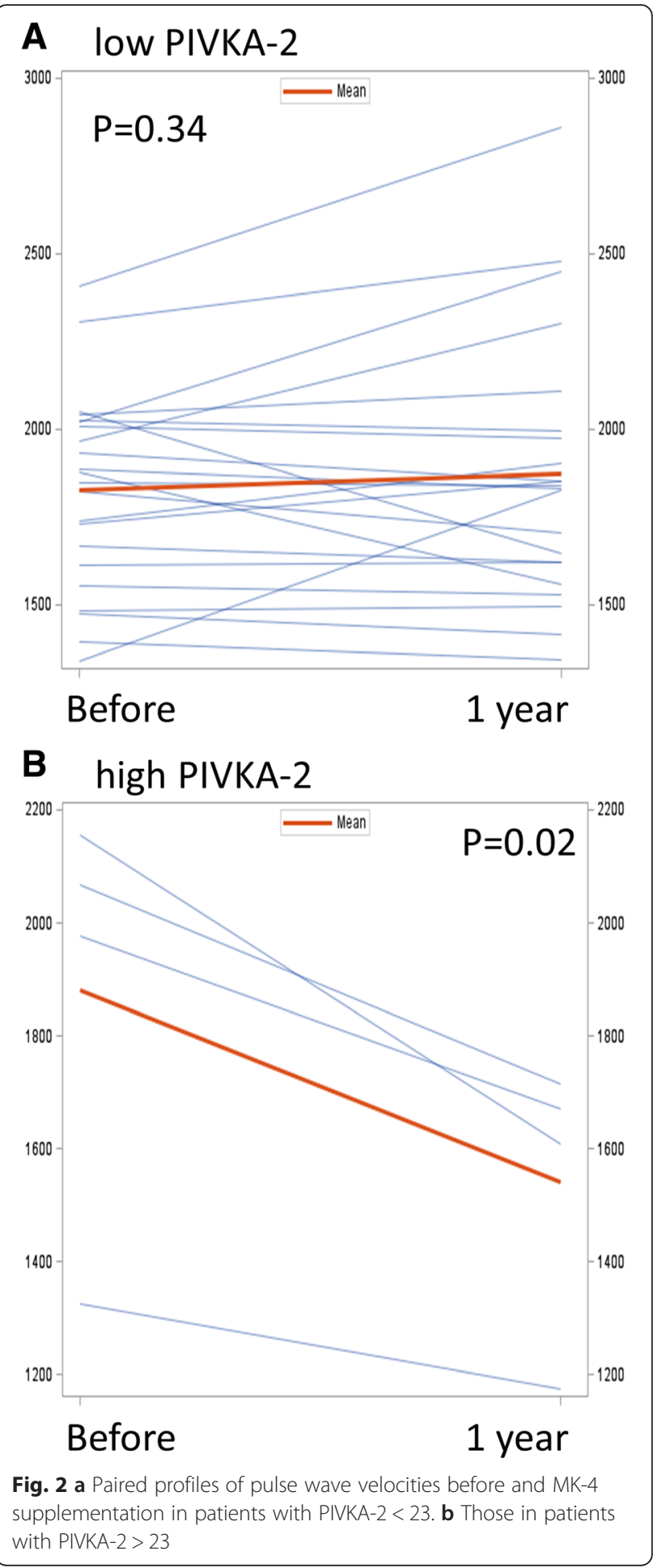

medical history, medication-use, body-mass index, scanner type and manufacturer [21]. This study showed $14 \%$ CAC increase annually, however it is unknown whether MK-4 supplementation retarded progression because this study lacks the control group. At the very least, MK-4 did not stop CAC progression. 

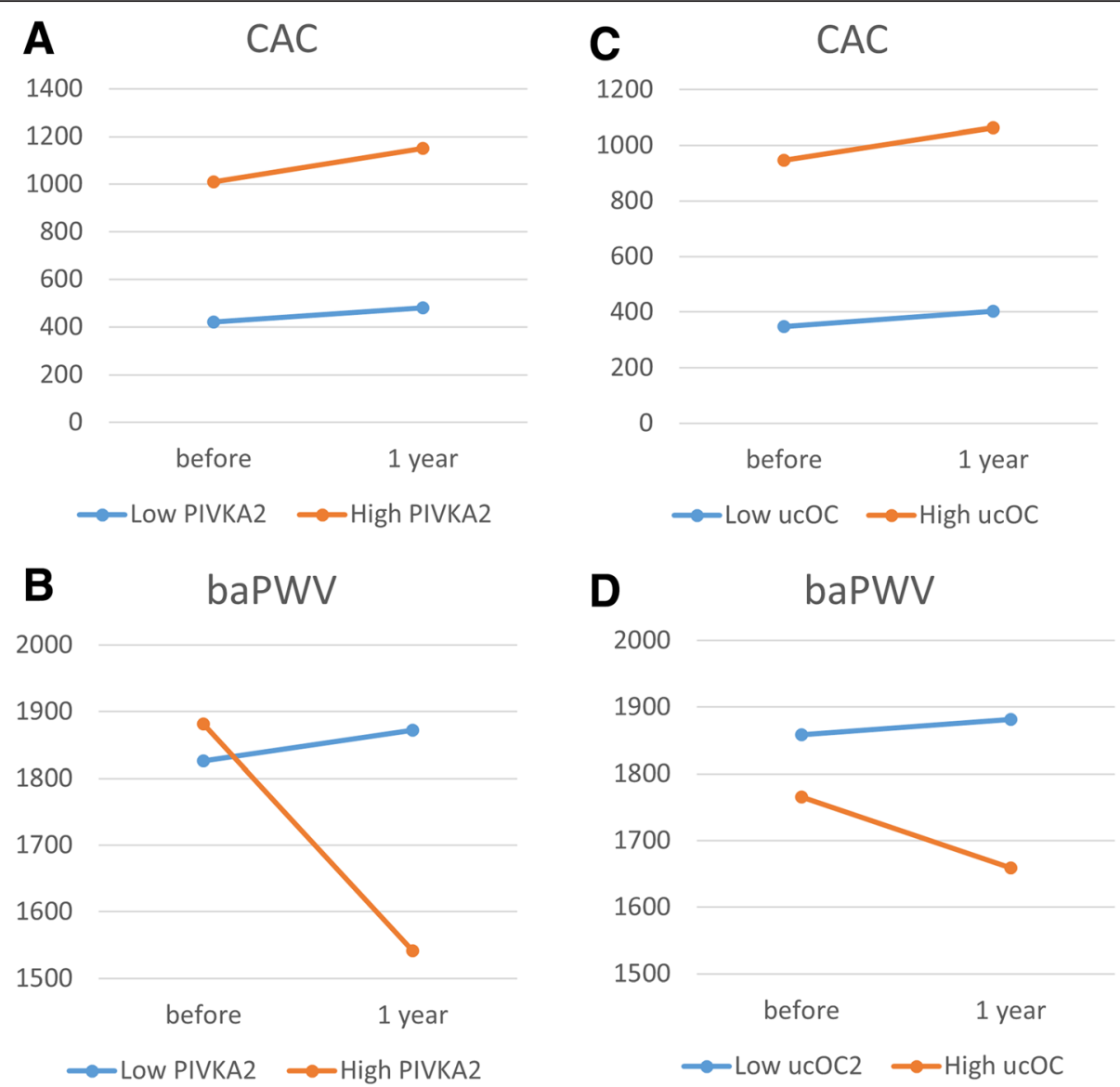

Fig. 3 Average values of CAC and baPWV before and after 1 year MK-4 supplementation. a CAC and (b) baPWV stratified by PIVKA-2 level. c CAC and (d) baPWV stratified by ucOC level

MK-7 supplementation significantly decreased dephospho-uncarboxylated MGP dose-dependently [14]. MK-7 supplements may help postmenopausal women to prevent bone loss [22]. Low-dose menaquinone-4 improves gamma-carboxylation of osteocalcin in young males [23]. Animal studies showed that high-dose MK-7 supplementation inhibits the development of cardiovascular calcification in rats [24]. Shea et al. reported that there was no difference in CAC progression between PK supplementation group and control group; the mean $( \pm$ SEM $)$ changes in Agatston scores were $27 \pm 6$ and $37 \pm 7$, respectively. A 270-day course of low-dose vitamin K2 (90 $\mu \mathrm{g} /$ day, MK-7) administration in patients with CKD stages 3-5 may reduce the progression of atherosclerosis, but does not significantly affect the progression of calcification [25]. On the other hand, this study is as high as high dose (45 mg/day, MK-4) The effective dose to protect atherosclerosis or calcifications is unknown.

In terms of arterial stiffness, long-term use of MK-7 supplements improves arterial stiffness in healthy postmenopausal women, especially in women having a high arterial stiffness [15]. The results of this study were similar to prior reports as have little preventive effects on CAC. On the other hand, effects on arterial stiffness were also observed in this study.

There are several limitations of this study. This study was a small number, single center and a single arm study. It is difficult to judge the effect of MK-4 because of the lack of a control group.

In conclusion, despite MK-4 supplementation, CAC progressed $14 \%$ annually. The arterial stiffness was not changed overall, but reduction was observed only in patients with baseline vitamin $\mathrm{K}$ insufficiency.

\section{Abbreviations}

baPWV: brachial ankle pulse wave velocity; CAC: coronary artery calcification; dp-uCMGP: dephospho-uncarboxylated matrix gla protein;

MK: menqauinone; PIVKA-2: protein induced by vitamin K absence or antagonist- 2; PK: phylloquinone; UCOC: uncarboxylated osteocalcin.

\section{Competing interests}

The authors declare that they have no competing interests.

\section{Authors' contribution}

YI participated in the study design, enrolled patients, performed statistical analysis and wrote the manuscript. ST participated in the design of the study and enrolled the patients. AS participated in the study design and made 
significant professional suggestions. TO participated in the study design, measured vitamin $\mathrm{K}$ levels and made professional suggestions. All authors read and approved the final manuscript.

\section{Acknowledgment}

We thank Ms. Chie Kato and Ms. Fumie Saito for clerical assistance.

\section{Funding}

This study was supported by Eizai Pharmaceutical Company. The funding donor has no role to analyze or interpret data.

\section{Author details}

'Department of Cardiovascular Medicine, Tokai University School of Medicine, 143 Shimokasuya, Isehara 259-1193, Japan. 'Department of Cardiovascular Medicine, Osaka City University Graduate School of Medicine, 1-5-7 Asahimachi, Abenoku, Osaka 545-0051, Japan. ${ }^{3}$ Department of Hygienic Sciences, Kobe Pharmaceutical University, 4-9-1 Motoyamakitamachi, Higashinadaku, Kobe 658-0003, Japan.

\section{Received: 27 February 2016 Accepted: 4 May 2016 \\ Published online: 12 May 2016}

\section{References}

1. Henein MY, Koulaouzidis G, Granasen G, Wiklund U, Guerci A, Schmermund A. The natural history of coronary calcification: a meta-analysis from St Francis and EBEAT trials. Int J Cardiol. 2013;168:3944-8.

2. Madhavan MV, Tarigopula M, Mintz GS, Maehara A, Stone GW, Genereux P. Coronary artery calcification: pathogenesis and prognostic implications. J Am Coll Cardiol. 2014;63:1703-14.

3. Budoff MJ, Shaw LJ, Liu ST, Weinstein SR, Mosler TP, Tseng PH, Flores FR, Callister TQ, Raggi P, Berman DS. Long-term prognosis associated with coronary calcification: observations from a registry of 25,253 patients. J Am Coll Cardiol. 2007:49:1860-70.

4. Luo G, Ducy P, McKee MD, Pinero GJ, Loyer E, Behringer RR, Karsenty G. Spontaneous calcification of arteries and cartilage in mice lacking matrix GLA protein. Nature. 1997;386:78-81.

5. Schurgers $\sqcup$, Uitto J, Reutelingsperger CP. Vitamin K-dependent carboxylation of matrix Gla-protein: a crucial switch to control ectopic mineralization. Trends Mol Med. 2013;19:217-26.

6. Schurgers $L$, Cranenburg EC, Vermeer C. Matrix Gla-protein: the calcification inhibitor in need of vitamin K. Thromb Haemost. 2008;100:593-603.

7. Rennenberg RJ, van Varik BJ, Schurgers $L$, Hamulyak K, Ten Cate H, Leiner T, Vermeer C, de Leeuw PW, Kroon AA. Chronic coumarin treatment is associated with increased extracoronary arterial calcification in humans. Blood. 2010;115:5121-3.

8. Weijs B, Blaauw Y, Rennenberg RJ, Schurgers LJ, Timmermans CC, Pison L, Nieuwlaat R, Hofstra L, Kroon AA, Wildberger J, Crijns HJ. Patients using vitamin $\mathrm{K}$ antagonists show increased levels of coronary calcification: an observational study in low-risk atrial fibrillation patients. Eur Heart J. 2011:32:2555-62.

9. Beulens JW, Bots ML, Atsma F, Bartelink ML, Prokop M, Geleijnse JM Witteman JC, Grobbee DE, van der Schouw YT. High dietary menaquinone intake is associated with reduced coronary calcification. Atherosclerosis. 2009;203:489-93

10. Geleijnse JM, Vermeer C, Grobbee DE, Schurgers LJ, Knapen MH, van de Meer IM, Hofman A, Witteman JC. Dietary intake of menaquinone is associated with a reduced risk of coronary heart disease: the Rotterdam Study. J Nutr. 2004;134:3100-5.

11. Shea MK, O'Donnell CJ, Hoffmann U, Dallal GE, Dawson-Hughes B, Ordovas JM, Price PA, Williamson MK, Booth SL. Vitamin K supplementation and progression of coronary artery calcium in older men and women. Am J Clin Nutr. 2009:89:1799-807.

12. Shea MK, Holden RM. Vitamin K status and vascular calcification: evidence from observational and clinical studies. Adv Nutr. 2012;3:158-65.

13. Braam LA, Hoeks AP, Brouns F, Hamulyak K, Gerichhausen MJ, Vermeer C. Beneficial effects of vitamins $D$ and $K$ on the elastic properties of the vessel wall in postmenopausal women: a follow-up study. Thromb Haemost. 2004:91:373-80

14. Dalmeijer GW, van der Schouw YT, Magdeleyns E, Ahmed N, Vermeer C, Beulens JW. The effect of menaquinone-7 supplementation on circulating species of matrix Gla protein. Atherosclerosis. 2012;225:397-402.
15. Knapen MH, Braam LA, Drummen NE, Bekers O, Hoeks AP, Vermeer C. Menaquinone-7 supplementation improves arterial stiffness in healthy postmenopausal women. A double-blind randomised clinical trial. Thromb Haemost. 2015;113:1135-44

16. Agatston AS, Janowitz WR, Hildner FJ, Zusmer NR, Viamonte Jr M, Detrano R. Quantification of coronary artery calcium using ultrafast computed tomography. J Am Coll Cardiol. 1990;15:827-32.

17. Budoff MJ, Achenbach S, Blumenthal RS, Carr JJ, Goldin JG, Greenland P, Guerci AD, Lima JA, Rader DJ, Rubin GD, et al. Assessment of coronary artery disease by cardiac computed tomography: a scientific statement from the American Heart Association Committee on Cardiovascular Imaging and Intervention, Council on Cardiovascular Radiology and Intervention, and Committee on Cardiac Imaging, Council on Clinical Cardiology. Circulation. 2006;114:1761-91.

18. Ghadri JR, Goetti R, Fiechter M, Pazhenkottil AP, Kuest SM, Nkoulou RN, Windler C, Buechel RR, Herzog BA, Gaemperli O, et al. Inter-scan variability of coronary artery calcium scoring assessed on 64-multidetector computed tomography vs. dual-source computed tomography: a head-to-head comparison. Eur Heart J. 2011;32:1865-74.

19. Suhara Y, Kamao M, Tsugawa N, Okano T. Method for the determination of vitamin $\mathrm{K}$ homologues in human plasma using high-performance liquid chromatography-tandem mass spectrometry. Anal Chem. 2005;77:757-63.

20. McCullough PA, Chinnaiyan KM. Annual progression of coronary calcification in trials of preventive therapies: a systematic review. Arch Intern Med. 2009;169:2064-70.

21. Vossen LM, Schurgers $\perp$, van Varik BJ, Kietselaer BL, Vermeer C, Meeder JG, Rahel BM, van Cauteren YJ, Hoffland GA, Rennenberg RJ, et al. Menaquinone-7 Supplementation to Reduce Vascular Calcification in Patients with Coronary Artery Disease: Rationale and Study Protocol (VitaK-CAC Trial). Nutrients. 2015;7:8905-15.

22. Knapen MH, Drummen NE, Smit E, Vermeer C, Theuwissen E. Three-year low-dose menaquinone-7 supplementation helps decrease bone loss in healthy postmenopausal women. Osteoporos Int. 2013:24:2499-507.

23. Nakamura E, Aoki M, Watanabe F, Kamimura A. Low-dose menaquinone-4 improves gamma-carboxylation of osteocalcin in young males: a nonplacebo-controlled dose-response study. Nutr J. 2014;13:85.

24. Scheiber D, Veulemans V, Horn P, Chatrou ML, Potthoff SA, Kelm M, Schurgers LJ, Westenfeld R. High-Dose Menaquinone-7 Supplementation Reduces Cardiovascular Calcification in a Murine Model of Extraosseous Calcification. Nutrients. 2015;7:6991-7011.

25. Kurnatowska I, Grzelak P, Masajtis-Zagajewska A, Kaczmarska M, Stefanczyk L Vermeer C, Maresz K, Nowicki M. Effect of vitamin K2 on progression of atherosclerosis and vascular calcification in nondialyzed patients with chronic kidney disease stages 3-5. Pol Arch Med Wewn. 2015;125:631-40.

\section{Submit your next manuscript to BioMed Central and we will help you at every step:}

- We accept pre-submission inquiries

- Our selector tool helps you to find the most relevant journal

- We provide round the clock customer support

- Convenient online submission

- Thorough peer review

- Inclusion in PubMed and all major indexing services

- Maximum visibility for your research

Submit your manuscript at www.biomedcentral.com/submit 